\title{
Identifying and Mapping Two DNA Markers Linked to the Gene Conferring Resistance to Pea Enation Mosaic Virus
}

\author{
J. Yu, ${ }^{1}$ W.K. Gu, ${ }^{1}$ R. Provvidenti, ${ }^{2}$ and N.F. Weeden ${ }^{1}$ \\ New York State Agricultural Experiment Station, Cornell University, Genevea, NY 14456
}

Additional index words. ASAP, RAPD, polymerase chain reaction, Pisum sativum, PEMV

\begin{abstract}
Two random amplified polymorphic DNA (RAPD) markers linked to $E n$, the gene conferring resistance to pea enation mosaic virus in pea, were identified and the DNA fragments were cloned and partially sequenced. Allele-specific associated primers for each cloned DNA fragment were developed and used in screening $F_{2}$ populations. One marker, P256 $_{900}$, mapped very near $A d h-1$, about $6 \mathrm{cM}$ from $E n$. The other marker, B500 $_{400}$, was located about $8 \mathrm{cM}$ from En on the same side as $\mathbf{P 2 5 6}_{900}$.
\end{abstract}

Identifying disease resistance genes and incorporating them into suitable germplasm are major challenges for plant breeders. Direct assays for disease resistance may be difficult to perform or may fail to identify specific resistance genes without extensive testing. Easily scored markers linked to such genes are recognized as valuable tool for plant breeders. Several types of molecular markers have been used to tag specific genes, including allozymes (Rick and Fobes, 1974), restriction fragment-length polymorphisms (RFLPs) (Young et al., 1988), (random amplified polymorphic DNA (RAPD) markers (Martin et al., 1991), sequencecharacterized amplified regions (SCARs) (Paran and Michelmore, 1992), and allele-specific associated primers (ASAPs) (Gu et al., 1995). The last technique is particularly appropriate for markerassisted selection on many individuals because it does not require electrophoresis of the amplified products. Rather, individuals possessing a specific sequence linked to the gene of interest are identified using primers specific to that sequence. When using ASAPs, generally a single DNA fragment is amplified and from only one of the alleles. These features permit visualization of DNA as a presence-absence assay directly in the reaction tubes or microtiter plate and eliminates the need to resolve fragments on agarose gels ( $\mathrm{Gu}$ et al., 1995). Because the amplification reactions can be performed in microtiter plates, 96 individuals can be conveniently analyzed in a few hours on standard equipment.

Identifying markers for direct detection of genes conferring resistance to viral diseases in pea (Pisum sativum L.) would aid breeding programs, particularly when several resistance genes are selected simultaneously. Pea enation mosaic virus (PEMV) is an important pathogen of the garden pea in many areas of the United States and western Europe. Resistance to PEMV is controlled by a single dominant gene, En (Schroeder and Barton, 1958). Homozygous susceptible genotypes can be identified by their characteristic mosaic pattern consisting of hyaline, translucent spots (windows) and small necrotic flecks, causing foliar reduction and distortion. Pods have ridged overgrowths (enations) and plants are stunted. Symptoms can be influenced by environmental conditions, with systemic symptoms mild or absent at temperatures

Received for publication 16 Nov. 1994. Accepted for publication 11 May 1995. This work was supported in part by a grant from the Cool Season Food Legume Program, administered by the Univ. of Idaho, Moscow. The cost of publishing this paper was defrayed in part by the payment of page charges. Under postal regulations, this paper therefore must be hereby marked advertisement solely to indicate this fact.

${ }^{1}$ Dept. of Horticultural Sciences.

${ }^{2}$ Dept. of Plant Pathology. above 25C. At temperature below $18 \mathrm{C}$, resistant plants may develop atypical symptoms, consisting of scattered chlorotic flecks (Schroeder and Barton, 1958). Thus, environmental variations can lead to misclassification of genotypes. This difficulty would be avoided and breeding for resistance facilitated if an easily storable marker or markers closely linked to En could be identified.

$E n$ is between st and uni on linkage group III (Gritton and Hagedom, 1980; Marx et al., 1985). The isozyme locus Adh-1 is about $5 \mathrm{cM}$ from $E n$ and can be used as a marker for the resistance gene (Weeden and Provvidenti, 1988). However, Adh-1 needs to be induced under anaerobic conditions and is scored most easily in root or seed extracts. In contrast, a DNA marker could be scored in many tissues, would not require special conditions, and might be more appropriate for large-scale screening.

In this paper we report two RAPD markers for resistance to PEMV, the development of ASAPs for each RAPD marker, and the location of the DNA sequences relative to En and other markers in the region.

\section{Materials and Methods}

Plant material. A set of $30 \mathrm{~F}_{5}$ recombinant inbred lines (RILs), segregating for resistance to PEMV, were derived by single-seed descent from the 'Alaska' x B880-221 $\mathrm{F}_{2}$ population described in Weeden et al. (1988). These RILs, their susceptible parent 'Alaska', and resistant parent B880-221 were used identify the RAPD markers.

Two $\mathrm{F}_{2}$ populations segregating for resistance to PEMV were tested with the RAPD primers P256 and B500: B 184-325 (= $\left.\mathrm{F}_{2}-\mathrm{A}\right)$ and $\mathrm{B} 180-748\left(=\mathrm{F}_{2}-\mathrm{B}\right) . \mathrm{F}_{2}-\mathrm{A}$ was polymorphic for the morphological markers $u n i, a p u$, and $s t$, as well as En and $\mathrm{P} 256 . \mathrm{F}_{2}-\mathrm{B}$ segregated for En, P256, and B500. A third $\mathrm{F}_{2}$ population, Adh-F x 'Almota' ( $=\mathrm{F}_{2}-\mathrm{C}$ ), segregated for $A d h-1$ and both RAPD markers but not for $E n$. This population was analyzed to determine the intensity of linkage between the markers and $A d h-1$. Seeds of $\mathrm{F}_{2}$ $A$ and $F_{2}-B$ were obtained from the collection of the late G.A. Marx, New York State Agricultural Experiment Station, Geneva. For the F2-C population, the Adh-F parent was one of the RIL lines homozygous for $E n / E n$ and the $A d h-1$ allele coding for the faster migrating allozyme. 'Almota' was provided by Crites Moscow Growers, Moscow, Idaho. Samples of the varieties 'Bolero,' 'Bemol,' 'Dinos,' 'Novella II,' 'Spring,' 'Stampede' and 'Tecoma' were obtained from David Webster, Asgrow Research Center, Twin Falls, Idaho.

Plants were grown in pots containing an artificial soil mix and 
Table 1. Segregation of En, P256 ${ }_{900}$, and $\mathrm{B}_{500_{40}}$ in the pea $\mathrm{F}_{5}$ recombinant inbred line population of 'Alaska' x B880-221.

\begin{tabular}{|c|c|c|c|c|c|c|}
\hline \multirow[b]{2}{*}{ Progeny } & \multirow[b]{2}{*}{ Total } & \multicolumn{4}{|c|}{ Plants with designated phenotype ${ }^{z}$ (no.) } & \multirow{2}{*}{$\begin{array}{c}\text { Recombination } \\
\text { ratio }\end{array}$} \\
\hline & & RIP & $\mathrm{R} / \mathrm{A}$ & $\mathrm{S} / \mathrm{P}$ & S/A & \\
\hline$\overline{\mathrm{P} 256_{900}}$ & 30 & 13 & 2 & 0 & 15 & 0.035 \\
\hline B $500_{400}$ & 30 & 11 & 4 & 0 & 15 & 0.077 \\
\hline
\end{tabular}

${ }^{2}$ Phenotypic designations: $\mathrm{R}=$ resistant, $\mathrm{S}=$ susceptible, $\mathrm{P}=$ band present, $\mathrm{A}=$ band absent,

maintained under greenhouse conditions. To test for resistance to PEMV, the first two fully expanded leaves of the seedlings were mechanically inoculated with virus. To ensure infection in susceptible genotypes, all plants were reinoculated 5 days later on the third and fourth leaves. Inoculum was prepared by grinding PEMV-infected leaves of a susceptible variety, 'Bonneville' with potassium phosphate buffer at $\mathrm{pH}$ 8.5. All controls, parental lines and 'Bonneville' were subjected to the identical inoculation procedure.

DNA isolation. Total genomic DNA was extracted from fresh leaf material by the method of Torres et al. (1993).

Bulked segregant analysis (BSA). BSA, as described by Michelmore et al. (1991), was performed as follows. Four samples ('Alaska', B880-221, a pooled resistant bulk, and a pooled susceptible bulk) were tested with each primer. Each bulk sample consisted of $5 \mathrm{mg}$ DNA from six RILs. The 10mer primers were obtained from the Biotechnology Center of Cornell Univ. and from the Univ. of British Columbia. Each of the promising primers was further tested by determining its segregation pattern in all 30 RILs.

$P C R$ procedure. Each RAPD reaction mixture contained 0.2 mM oligonucleotide primer, $0.13 \mathrm{~mm}$ of each of four dNTP, $10 \mathrm{ng}$ of template DNA, $2.5 \mathrm{ml} \mathrm{10x}$ buffer with $1.25 \mathrm{mM} \mathrm{MgCl}_{2}$, and 0.5 unit of Taq polymerase (Promega, Madison, Wis.) in $18 \mathrm{ml}$ of sterilized distilled water, making a total volume of $25 \mathrm{ml}$. The profile was run on a programmable thermal controller (model 60 PTC-100; MJ Research, Watertown, Mass.) and consisted of 40 cycles at 94,37 , and $72 \mathrm{C}$ for 1,2 , and $2 \mathrm{~min}$, respectively, followed by $8 \mathrm{~min}$ at $72 \mathrm{C}$. Gels were stained with $0.001 \mathrm{mg} \cdot \mathrm{ml}^{-1}$ ethidium bromide and photographed under ultraviolet (UV) light.

Cloning and sequencing of the DNA markerfragments. The TA Cloning Kit (Invitrogen Corp., San Diego) was used to clone the two RAPD markers identified by BSA and RIL screening. The procedure was as described by the manufacturer. For the B500 marker, the RAPD fragment was isolated and reamplified. One microliter of the amplified product was used directly for ligation. To clone the P256 marker, $2 \mathrm{ml}$ undiluted polymerase chain reaction (PCR) product, containing the desired RAPD fragment and several others, was used in the ligation reactions, and the ligation was performed at $12 \mathrm{C}$ overnight. Recombinant clones generated from this second ligation were screened for the appropriate size insert before sequencing.

Both ends of each DNA insert were sequenced using an automated sequencer (ABI 373; Applied Biosystems). The procedure followed that of $\mathrm{Gu}$ et al. (1995), except that each sequence reaction contained $9 \mathrm{ml}$ premixture, $5 \mathrm{ml}$ of $0.05 \mathrm{mg}$ template DNA, and 10 ng M13 universal primer.

Development of ASAPs. Oligonucleotides matching the first 18 to 24 bases of each end of the two RAPD markers were synthesized at the Cornell Biotechnology facilities. The precise length of these oligonucleotides depended on the DNA sequence near what would become the 3' end of the primer. For stronger annealing at the 3' end, the final nucleotide was either guanosine or cytosine. The paired oligomers were tested for their ability to amplify at annealing temperatures between 60 and $68 \mathrm{C}$, a single fragment when DNA from the resistant individuals was used as template and no fragment when DNA from the susceptible individuals was used as template. Primer pairs that met these criteria were used to screen the three $\mathrm{F}_{2}$ populations. For the ASAP amplifications, cycle

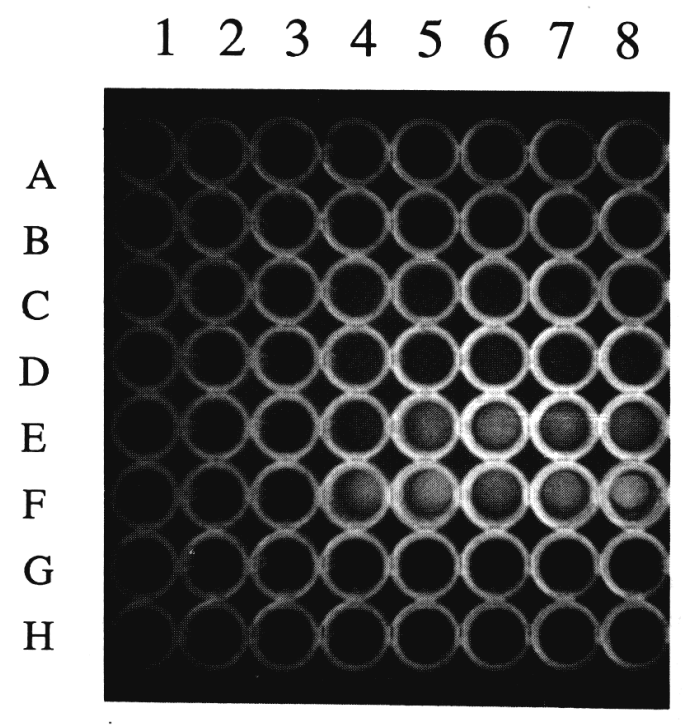

\section{$\begin{array}{llllllll}1 & 2 & 3 & 4 & 5 & 6 & 7 & 8\end{array}$}

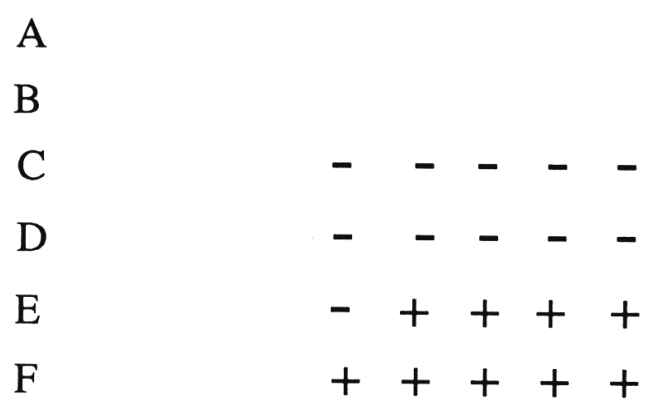

G

H

Fig. 1. Direct staining of amplification products in an allele-specific associated primer (ASAP) analysis for the En marker. The ASAPs used were those constructed from the P256 ${ }_{900}$, fragments. Rows A, B, G, and $\mathrm{H}$ and columns 1-3 in rows $C, D, E$, and F are blanks. Wells 4-8 in rows $C$ and $D$ and well 4 in row $\mathrm{E}$ each contained template DNA from a different pea enation mosaic virussusceptible plants from the recombinant inbred line population of 'Alaska' $\mathrm{x}$ B880-221. Wells 5-8 in row E and wells 4-8 in row F contained template DNA from nine resistant plants, respectively, from the same RIL population. Our scoring of the fluorescence pattern is shown in the diagram in the lower part of the figure (plus = fluorescence, minus = lack of fluorescence). 
Table 2. Segregation of $E n, \mathrm{P} 256_{900}$, and $\mathrm{B} 500_{400}$, in pea $\mathrm{F}_{2}$ populations examined.

\begin{tabular}{|c|c|c|c|c|c|c|}
\hline \multirow[b]{2}{*}{ Locus } & \multirow[b]{2}{*}{ Total } & \multicolumn{4}{|c|}{ Plants with designated phenotype (no.) } & \multirow{2}{*}{$\begin{array}{c}\text { Recombination } \\
\text { ratio } \\
\end{array}$} \\
\hline & & $\mathrm{R} / \mathrm{P}$ & $\mathrm{R} / \mathrm{A}$ & $\mathrm{S} / \mathrm{P}$ & S/A & \\
\hline \multicolumn{7}{|l|}{ F2-A } \\
\hline $\begin{array}{l}\text { P 2 56 } \\
\text { F2-B }\end{array}$ & 76 & 53 & 3 & 2 & 18 & 0.066 \\
\hline P $256_{900}$ & 60 & 42 & 3 & 0 & 15 & 0.050 \\
\hline B $500_{400}$ & 60 & 41 & 4 & 0 & 15 & 0.067 \\
\hline
\end{tabular}

${ }^{\overline{ }}$ Phenotypic designations: $\mathrm{R}$ = resistant, $\mathrm{S}=$ susceptible, $\mathrm{P}=$ band present, $\mathrm{A}=$ band absent.

Table 3. Segregation of $A d h-1, \mathrm{P} 256_{900}$, and $\mathrm{B} 500_{400}$ in the pea $\mathrm{F}_{2}$ progeny from Adh-F $\mathbf{x}$ 'Almota'.

\begin{tabular}{|c|c|c|c|c|c|c|c|c|}
\hline \multirow[b]{2}{*}{ Loci } & \multirow[b]{2}{*}{ Total } & \multicolumn{6}{|c|}{ Plants with designated phenotype" (no.) } & \multirow{2}{*}{$\begin{array}{c}\text { Recombination } \\
\text { ratio }\end{array}$} \\
\hline & & R IP & F/A & HIP & $\mathrm{R} / \mathrm{A}$ & SIP & S/A & \\
\hline$\overline{A d h-1: \mathrm{P} 256_{900}}$ & 82 & 1 & 16 & 41 & 0 & 24 & 0 & 0.012 \\
\hline Adh-1 : ${\mathrm{B} 500_{400}}$ & 82 & 1 & 16 & 41 & 0 & 24 & 0 & 0.012 \\
\hline
\end{tabular}

Phenotypic designations: $\mathrm{F}=$ homozygous fast, $\mathrm{H}=$ heterozygous, $\mathrm{S}=$ homozygous slow, $\mathrm{P}=$ band present, $\mathrm{A}=$ band absent.

parameters were 94C for 2 min followed by 35 cycles of 94C for $35 \mathrm{sec}$ and $64 \mathrm{C}$ for $3 \mathrm{~min}$ with a final extension of $64 \mathrm{C}$ for $6 \mathrm{~min}$.

Linkage analysis. The segregation data were analyzed using the computer program JOINMAP (Stam, 1993).

\section{Results}

A total of 270 random oligonucleotide primers (10mers) was screened by BSA. Of these, 30 primers produced polymorphism between the susceptible and resistant bulks and between the two parents. Two of the primers, designated B500 (5'-TTGCGTCATG) and P256 (5'-GATCCACGGA), amplified DNA fragments of 400 and $900 \mathrm{bp}$, respectively, differed consistently between the resistant and susceptible RILs. Joint segregation analysis indicated that, in these RILs, the recombinant ratio between ${\mathrm{B} 500_{400}}$ and $E n$ was about $8 \%$ and between $E n$ and $\mathrm{P} 256_{900}$ was about $4 \%$ (Table 1).

When $\mathrm{P} 256_{900}$ and $\mathrm{B} 500_{400}$ were excised from the gel and used as DNA templates for PCR with respective primers, $\mathrm{B} 500_{400}$ generated a single 400-bp fragment, whereas $\mathrm{P} 256_{900}$ generated several small fragments in addition to the expected 900-bp fragment. Recombinant clones carrying these smaller fragments could be easily eliminated after transformation.

Transformation with the $\mathrm{B} 500_{400}$ ligation mix generated more than 100 colonies harboring recombinant plasmids. Of the 15 colonies examined, 9 possessed plasmids with the correct insert size. The transformation involving ligated $\mathrm{P} 256_{900}$ marker gave only one out of 18 white clones with the desired fragment. About $250 \mathrm{bp}$ from either end of the DNA insets were sequenced.

The two primers synthesized for the $\mathrm{B} 500_{400}$ ASAP were a 21mer (5'-TTGCGTCATGAAACCTTGTGC) and a 19mer (5'TTGCGTCATGGTTCCGGGG). For the P256 ${ }_{900}$ fragment, the two primers were a $24 \mathrm{mer}$ (5'-GATCCACGGAATCACACCATTTAC) and a 23mer (5'-GATCCACGGACAAAAGGGAAAGC). Each pair of primers was used to survey the PEMV-susceptible and PEMV-resistant RILs. For each pair, a single DNA fragment was amplified when DNA of the resistant parent was used as a template but not when DNA of susceptible parents was used, thus making the primers suitable for use as ASAPs. When the primers were used in an ASAP format in which ethidium bromide was added directly to the microtiter plate and the individual wells were examined under a UV light for fluorescence, the presence and absence of fluorescence matched that observed for the presence or absence of an amplified fragment. Thus, wells exhibiting fluorescence corresponded to those samples taken from plants resistant to PEMV, and those lacking fluorescence were from susceptible individuals (Fig. 1).

The $\mathrm{P} 256_{900}$ marker segregated in each of the $\mathrm{F}_{2}$ populations examined, whereas the $\mathrm{B} 00_{400}$ fragment segregated only in $\mathrm{F}_{2}$ - $\mathrm{B}$ and $\mathrm{F}_{2}-\mathrm{C}$ (Tables 2 and 3 ). The F2-A population segregated for several standard markers (uni, st, apu) located near En on the pea linkage map, permitting an accurate localization of the $\mathrm{P} 256_{900}$ sequence. The marker mapped about $6 \mathrm{cM}$ from $E n$ on the side

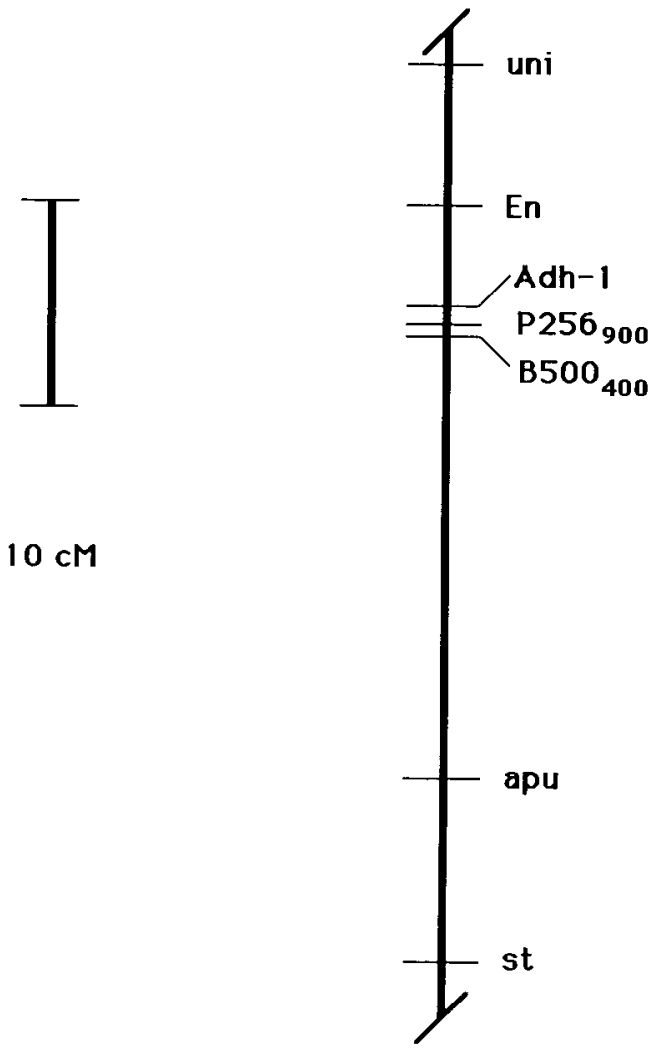

Fig. 2. The locations of $\mathrm{B} 500_{400}$ and $\mathrm{P} 256_{900}$ markers on linkage group III of pea. The precise position of $s t$ could not be determined from our data, but $s t$ is known to lie about $10 \mathrm{cM}$ from ари (Marx, 1986). 
Table 4. Distribution of markers in some pea varieties and breeding lines.

\begin{tabular}{lccc}
\hline & $E n$ & $\mathrm{~B} 500_{400}$ & $\mathrm{P} 256_{900}$ \\
\hline Adh-F & Resistant & $\mathrm{A}$ & $\mathrm{A}$ \\
Alaska & Susceptible & $\mathrm{A}$ & $\mathrm{A}$ \\
Almota & Susceptible & $\mathrm{A}-$ & $\mathrm{A}$ \\
B880-221 & Resistant & $\mathrm{P}$ & $\mathrm{P}$ \\
Bemol & Susceptible & $\mathrm{A}$ & $\mathrm{P}$ \\
Bolero & Susceptible & $\mathrm{A}$ & $\mathrm{A}$ \\
Dinos & Susceptible & $\mathrm{A}$ & $\mathrm{A}$ \\
Novella II & Resistant & $\mathrm{P}$ & $\mathrm{P}$ \\
S pring & Susceptible & $\mathrm{A}$ & $\mathrm{A}$ \\
Stampede & Susceptible & $\mathrm{A}$ & $\mathrm{A}$ \\
Tecoma & Susceptible & $\mathrm{A}$ & $\mathrm{A}$ \\
\hline
\end{tabular}

${ }^{\mathrm{P}}=$ band present, $\mathrm{A}=$ band absent.

opposite uni (Table 2, Fig. 2). The intensity of the En/ $\mathrm{P} 256_{900}$ linkage was confirmed in population $\mathrm{F}_{2}-\mathrm{B}$ (Table 2), and $\mathrm{B} 50_{400}$ was shown to map about $2 \mathrm{cM}$ further from $E n$ on the same side as $\mathrm{P} 256_{900}$. Because both of these locations were close to the reported position of $A d h-1$, we directly compared the relative positions of the three markers using F2-C. The two ASAP products cosegregated in $\mathrm{F}_{2}-\mathrm{C}$, and only one recombinant was observed in joint segregation analysis between either ASAP product and Adh-1 (Table 3).

The markers were not absolutely associated with the En gene in the germplasm sample we analyzed (Table 4). Most susceptible lines lacked the markers, but we also observed the presence of P256 ${ }_{900}$ in 'Bemol' (Table 4) and in certain other susceptible lines in our collection (data not presented). Conversely, most of the resistant lines possessed one or both markers, the main exception being our Adh-F line (Table 4), which had been selected specifically because it displayed recombination between En and Adh-1.

\section{Discussion}

We have identified two DNA markers linked to the gene conferring resistance to PEMV and developed ASAPs for these markers. The ASAPs efficiently and conveniently distinguish between plants possessing En and those homozygous en/en (susceptible to PEMV). Because the DNA fragment is generated in homozygous En and heterozygous plants, this method cannot distinguish between these two genotypes. However, screening with the P256 ${ }_{900}$ ASAP is as accurate and much faster than either direct screening in the greenhouse or indirect screening using the $\mathrm{ADH}$ allozyme polymorphism. As was described by $\mathrm{Gu}$ et al. (1995) DNA can be extracted directly from imbibed seed and requires about $3 \mathrm{~h}$ of technician time per 100 samples.

The gene conferring resistance to PEMV originated from a single plant of PI 140295 (Schroeder and Barton, 1958). A marker in the original plant tightly linked to $E n$ would be useful because it would be applicable in nearly all breeding programs. Unfortunately, P256 $6_{900}$ displays a significant recombination rate with $E n$. Despite this limitation, the breeder should be able to select parental lines polymorphic for the presence-absence of the marker, thereby allowing the tagging of the En gene. Resistant lines, such as Adh$\mathrm{F}$, have been developed that lack the marker, and a few susceptible lines were found that possessed either or both $\mathrm{P} 256_{900}$ and $\mathrm{B} 500_{400}$.
Clearly, a determination of the marker genotype in the parental lines would be necessary before applying the ASAP technique to a population segregating for $E n$. As the fast allozyme of $A d h-1$ is rare in cultivated pea germplasm and is not usually linked to En (Weeden and Provvidenti, 1988), we suggest that $\mathrm{P}_{256}$ and $\mathrm{B} 500_{400}$ will, in general, be more useful as markers for En than Adh-1.

Our survey of primers did not identify any RAPD markers mapping on the uni side of En. Although uni is an easily scored morphological marker (Lamprecht, 1933), it is not acceptable in commercial varieties because of its effect on leaf area and fertility. Thus, if uni were used to tag En, this marker gene would have to be eliminated from the line before the line could be released as a variety. Hofer et al. (1994) recently reported a cDNA clone (Peaflo) that maps very near uni. The use of this marker in combination with $\mathrm{P} 256_{900}$ would permit a highly accurate screening for $E n$, for there would be markers within $8 \mathrm{cM}$ on each side of the resistance gene, and the anticipated error rate due to recombination would be less than one in 100 .

\section{Literature Cited}

Gritton, E.T. and D.J. Hagedom. 1980. Linkage of the En and st genes in peas. Pisum Nwsl. 12:26-27.

Gu, W-K., N.F. Weeden, J. Yu, and D.H. Wallace. 1995. Large scale, costeffective screening of PCR products in marker-assisted selection applications. Theor. Appl. Genet. (In press.)

Hofer, J., A. Michael, R. Helleas, L. Turner, M. Ambrose, and N. Ellis. 1994. Characterization of a floricaula/leafy homologue from Pisum sativum. 4th Intl. Congr. Plant Mol. Biol. p. 725. (Abstr.)

Lamprecht, H. 1933. Ein unifoliata- Typus von Pisum mit gleichzeitiger Pistilloidie. Hereditas 18:56-64.

Martin, G., J.G.K. Williams, and S.D. Tanksley. 1991. Rapid identification of markers linked to a Pseudomonas resistance gene in tomato by using random primers and near-isogenic lines. Proc. Natl. Acad. Sci. USA $88: 2336-2340$.

Marx, G.A., N.F. Weeden, and R. Provvidenti. 1985. Linkage relationships among markers in chromosome 3 and $E n$, a gene conferring virus resistance. Pisum Nwsl. 17:57-60.

Michelmore, R.W., I. Paran, and R.V. Kesseli. 1991. Identification of markers linked to disease-resistance genes by bulked segregate analysis: A rapid method to detect markers in specific genomic regions by using segregating populations. Proc. Natl. Acad. Sci. USA 88:9828-9832.

Paran, I. and R.W. Michelmore. 1992. Development of reliable PCRbased markers linked to downy mildew resistance genes in lettuce. Theor. Appl. Genet. 85:985-993.

Rick, C.M. and J.F. Fobes. 1974. Association of an allozyme with nematode resistance. Tomato Genet. Coop. Rpt. 24:25.

Schroeder, W.T. and D.W. Barton. 1958. The nature and inheritance of resistance to the pea enation mosaic virus in garden pea, Pisum sativum L. Phytopathology 48:628-632.

Stam, P. 1993. Construction of integrated genetic linkage maps by means of a new computer package: JoinMap. Plant J. 3:739-744.

Torres, A., N.F. Weeden, and A. Martin. 1993. Linkage among isozyme, RFLP and RAPD markers in Vicia faba. Theor. Appl. Genet. 85:937945.

Weeden, N.F. and R. Provvidenti. 1988. A marker locus, Adh-1, for resistance to pea enation mosaic virus in Pisum sativum. J. Hered. 79:128-131.

Young, N.D., D. Zamir, M.W. Ganal, and S.D. Tanksley. 1988. Use of isogenic lines and simultaneous probing to identify DNA markers tightly linked to the $T M-2 a$ gene. Genetics 120:579-586. 